\title{
PEMBELAJARAN PENDIDIKAN KEWARGANEGARAAN BERBASIS KARAKTER DI SD 004 BANGKINANG
}

\author{
Mufarizuddin $^{1}$, Moh. Fauziddin ${ }^{2}$, M. Syahrul Rizal ${ }^{3}$ \\ 1) Program Studi PGSD, Fakultas Ilmu Pendidikan , Universitas Pahlawan Tuanku Tambusai \\ e-mail: zuddin.unimed@gmail.com \\ 2) Program Studi PGPAUD, Fakultas Ilmu Pendidikan, Universitas Pahlawan Tuanku Tambusai \\ e-mail: mfauziddin@gmail.com \\ 3) Program Studi PGSD, Fakultas Ilmu Pendidikan, Universitas Pahlawan Tuanku Tambusai \\ e-mail: syahrul.rizal92@gmail.com
}

\begin{abstract}
ABSTRAK
Pengelolaan karakter pembelajaran PKn di SD 004 Bangkinang. Penelitian ini dilakukan di SD 004 Bangkinang menggunakan observasi, wawancara dan dokumentasi. Validitas data dalam penelitian adalah trianglasi. Hal ini di tunjukkan bahwa Guru tidak memahami (1) perencanaan pembelajaran PKn Berbasis Karakter di SD 004 Bangkinang dilakukan dengan menyusun rencana pembelajaran berdasarkan standar kompetensi dan kompetensi dasar pelajaran PKn untuk memfasilitasi guru ketika memasukkan nilai karakter yang akan diberikan kepada siswa. Nilai karakter dalam rencana pelajaran didasarkan pada standar kompetensi. (2) Pelaksanaan pembelajaran Kewarganegaraan Berbasis Karakter dilihat dari proses pembelajaran yang terdiri dari tiga tahap. Belajar dimulai dengan kegiatan pembukaan yang terdiri dari berdoa dan menyanyikan lagu nasional. Kegiatan inti terdiri dari eksplorasi, elaborasi dan konfirmasi. Nilai-nilai karakter untuk kegiatan eksplorasi termasuk rasa ingin tahu, semangat nasionalisme dan patriotisme. Nilai-nilai karakter untuk kegiatan elaborasi termasuk keberanian, kepercayaan diri dan kerja sama. Penutupan dilakukan dengan berdoa dan menyapa sebelum meninggalkan ruang kelas. (3) Evaluasi pembelajaran Kewarganegaraan Berbasis Karakter di SD 004 Bangkinang terdiri dari dua kegiatan, penilaian kognitif, dan penilaian afektif. Penilaian kognitif dilakukan dengan memberikan pertanyaan berdasarkan standar kompetensi dan kompetensi dasar. Sedangkan penilaian efektif dilakukan dengan menggunakan lembar observasi berdasarkan nilai karakter yang dicapai. Dan dari penilaian ini, dapat ditemukan tingkat nilai karakter bangsa yang dicapai oleh siswa.
\end{abstract}

Kata kunci: Pendidikan Kewarganegaraan, Siswa, Karakter

\begin{abstract}
ABSTRCT
Management of the characters learning PKn in SD 004 Bangkinang. This research was conducted in SD 004 Bangkinang using observation, interview and documentation. The validity of the data in the study is trianglasi. It is shown that the Teacher did not understand (1) the planning of learning PKn-Based Characters in SD 004 Bangkinang done by compiling a learning plan based on competency standard and basic competence of subjects of PKn to facilitate the teacher when entering the character value that will be given to students. The value of the characters in the lesson plans based on standards of competence. (2) the Implementation of learning-Based Citizenship Character seen from the learning process consists of three stages. Learning begins with the opening activity that consists of praying and singing the national anthem. The core activities consist of the exploration, elaboration and confirmation. Value-the character value to the activities of exploration, including the curiosity, the spirit of nationalism and patriotism. Value-the character value to the activities of elaboration, including courage, self-confidence and cooperation. Closing is done by praying and say hello before leaving the classroom. (3) Evaluation of learning-Based Citizenship Characters in SD 004 Bangkinang consists of two activities, cognitive assessment, and assessment of the affective. Cognitive assessment was done by giving questions based on the standard competence and basic competence. While the assessment is effectively carried out by
\end{abstract}


using the observation sheet based on the value of the character is achieved. And from this assessment, can be found level the value of the character of the nation achieved by the students.

Keywords: Citizenship Education, Students, Characters

\section{PENDAHULUAN}

Pendidikan Kewarganegaraan merupakan mata pelajaran yang secara umum bertujuan untuk mengembangkan potensi individu warga negara Indonesia, sehingga memiliki wawasan, sikap, dan keterampilan kewarganegaraan yang memadai dan memungkinkan untuk berpartisipasi secara cerdas dan bertanggung jawab dalam berbagai kehidupan bermasyarakat, berbangsa dan bernegara.

Secara garis besar mata pelajaran Kewarganegaraan memiliki 3 dimensi yaitu (a) Dimensi Pengetahuan Kewarganegaraan (Civics Knowledge) yang mencakup bidang politik, hukum dan moral, (b) Dimensi Keterampilan Kewarganegaraan (Civics Skills) meliputi keterampilan partisipasi dalam kehidupan berbangsa dan bernegara, (c) Dimensi Nilai-nilai Kewarganegaraan (Civics Values) mencakup antara lain percaya diri, penguasaan atas nilai religius, norma dan moral luhur. (Depdiknas 2003:4)

Minat belajar siswa pada bidang PKn ini perlu mendapat perhatian khusus karena minat merupakan salah satu faktor penunjang keberhasilan proses belajar. Disamping itu minat yang timbul dari kebutuhan siswa merupakan faktor penting bagi siswa dalam melaksanakan kegiatan-kegiatan atau usahanya. Oleh karena itu minat belajar siswa harus diperhatikan dengan seksama. Hal ini untuk memudahkan membimbing dan mengarahkan siswa belajar, sehingga siswa mempunyai dorongan dan tertarik untuk belajar.

Pendidikan karakter adalah suatu sistem penanaman nilai-nilai karakter kepada warga sekolah yang meliputi komponen pengetahuan, kesadaran atau kemauan, dan tindakan untuk melaksanakan nilai-nilai tersebut. Pendidikan karakter dapat dimaknai sebagai "the deliberate use of all dimensions of school life to foster optimal character development". Dalam pendidikan karakter di sekolah, semua komponen (pemangku pendidikan) harus dilibatkan, termasuk komponen-komponen pendidikan itu sendiri, yaitu isi kurikulum, proses pembelajaran dan penilaian, penanganan atau pengelolaan mata pelajaran, pengelolaan sekolah, pelaksanaan aktivitas atau kegiatan ko-kurikuler, pemberdayaan sarana prasarana, pembiayaan, dan ethos kerja seluruh warga sekolah/lingkungan. Di samping itu, pendidikan karakter dimaknai sebagai suatu perilaku warga sekolah yang dalam menyelenggarakan pendidikan harus berkarakter. Pengertian karakter menurut Pusat Bahasa Depdiknas adalah "bawaan, hati, jiwa, kepribadian, budi pekerti, perilaku, personalitas, sifat, tabiat, temperamen, watak". Adapun berkarakter adalah berkepribadian, berperilaku, bersifat, bertabiat, dan berwatak" (Sudrajat, 2010: 1).

Penyelenggaraan pendidikan karakter di sekolah harus berpijak kepada nilai-nilai karakter dasar, yang selanjutnya dikembangkan menjadi nilai-nilai yang lebih banyak atau lebih tinggi (yang bersifat tidak absolut atau bersifat relatif) sesuai dengan kebutuhan, kondisi, dan lingkungan sekolah itu sendiri. Nilai merupakan suatu sifat dari suatu hal yang berhubungan dengan subjek yang berharga (Abdulkarim, 2004: 35). Menurut Hidayat (2009: 17) nilai didefinisikan berdasarkan disiplin ilmu pengetahuan dan pengertian nilai juga dapat ditemukan dalam kebijakan.

Nilai nasionalisme adalah nilai-nilai yang paling baik bagi bangsa Indonesia yang menggambarkan aktivitasnya. Nilai-nilai yang dimaksud adalah nilai-nilai yang bersumber pada kemerdekaan Indonesia 17 Agustus 1945 yang merupakan pantulan tekad bangsa Indonesia nuntuk merdeka, cetusan jiwa, dan semangat Pancasila yang telah berabad-abad lamanya tertindas oleh penjajah. Nilai-nilai tersebut meliputi (a) Nilai rela berkorban, (b) Nilai persatuan, (c) Nilai harga menghargai, (d) Nilai kerja sama, (e) Nilai bangga sebagai bangsa Indonesia. (Budiyanto, 2006: 32).

Para pakar pendidikan pada umumnya sependapat tentang pentingnya upaya peningkatan pendidikan karakter pada jalur pendidikan formal. Namun demikian, ada perbedaan-perbedaan pendapat di antara mereka tentang pendekatan dan modus pendidikannya. Berhubungan 
dengan pendekatan, sebagian pakar menyarankan penggunaan pendekatan-pendekatan pendidikan moral yang dikembangkan di negara-negara barat, seperti: pendekatan perkembangan moral kognitif, pendekatan analisis nilai, dan pendekatan klarifikasi nilai. Sebagian yang lain menyarankan penggunaan pendekatan tradisional, yakni melalui penanaman nilai-nilai sosial tertentu dalam diri peserta didik.

Bertolak dari pemikiran tersebut di atas, dan mengingat pentingnya proses pembelajaran PKn maka peneliti tertarik untuk mengangkat sebuah pelatihan kepada guru guru di SD 004 Bangkinang yang berjudul "Pembelajaran Pkn Berbasis Karakter"

\section{METODE}

Metode yang digunakan dalam pengabdian masyarakat ini adalah dengan melakukan a) Perncanaan, b) Pelaksanaan, c) Observasi dan Evaluasi, dan d) refleksi

\section{HASIL DAN PEMBAHASAN}

\section{Karakteristik Perencanaan Pembelajaran Pkn Berbasis Karakter di SD 004 Bangkinang}

Pendidikan Kewargarganegaraan ( $\mathrm{PKn})$ merupakan mata pelajaran yang mencakup proses penyiapan generasi muda untuk mengambil peran dan tanggung jawabnya sebagai warga negara, dan secara khusus, peran pendidikan termasuk di dalamnya persekolahan, pengajaran dan belajar,dalam proses penyiapan warga negara tersebut. PKn berbasis karakter bangsa adalah pelajaran PKn yang didalamnya memuat nilai-nilai dari pancasila dengan tujuan agar para siswa dalam menerapkan nilai-nilai terebut dalm kehidupannya sehari-hari.

Dalam kegiatan perencanaan guru akan melihat standar kompetensi (SK) dan kompetensi pembelajaran (KD) mata pelajaran PKn terlebih dahulu. Kemudian nilai-nilai dari pancasila yang akan diajarkan kepada siswa. Tujuannya adalah agar siswa mampu melaksanaan nilai-nilai tersebut dalam kehidupan sehari-hari. Penyusunan RPP dilakukan oleh guru SD 004 Bangkinang dengan mencantumkan nilai-nilai karakter bangsa yang disesuaikan dengan SK dan KD. Sebagai contoh untuk SK mendeskripsikan pengertian budaya politik, nilai karakter yang akan ditanamkan adalah religius, toleransi, disiplin, kerja keras, rasa ingin tahu, semangat kebangsaan, menghargai prestasi, dan tanggung jawab.

Standar kompetensi (SK) dan kompetensi dasar (KD) dalam pelajaran PKn tertuang dalam Rencana Pelaksanaan Pembelajaran (RPP). Pentingnya pembuatan rencana dalam pembelajaran oleh guru juga dibenarkan oleh Kennedy, Kerry J. (2002) dalam penelitiannya yang berjudul "Teachers' Conversations about Civic Education: Policy and Practice in Australian Schools". Penelitian ini dilaksanakan di negara Australia yang membahas tentang pentingnya perencanaan dalam kegiatan pembelajaran kewarganegaraan. Perencanaan tersebut disesuaikan dengan kurikulum yang ada di sekolah. Dalam pembuatan perencanaan tersebut dibutuhkan adanya guru yang berkompeten dibidangnya. Sehingga perencanaan pembelajaran yang dibaut dapat mencakup semua aspek tentang kewarganegaraan.

Hasil penelitian Kennedy (2002) di atas memiliki persamaan dan perbedaan dengan penelitian ini. Persamaannya adalah pentingnya pembuatan perencanaan pembelajaran sebelum proses KBM dilaksanakan. Perencanaan pembelajaran atau RPP dibuat berdasarkan pada kurikulum yang berlaku. Perbedaannya adalah dalam hasil penelitian ini menunjukkan bahwa guru memasukkan nilai-nilai karakter bangsa dalam pembuatan RPP.

Selain pembuatan silabus dan RPP, dalam kegiatan perencanaan pembelajaran guru juga harus memperhatikan kalender akademik untuk membuat program semester (promes) dan program tahunan (Prota) ynag mengacu pada kalender akademik.

2. Karakteristik Implementasi Pembelajaran Pkn Berbasis Karakter di SD 004 Bangkinang.

Pelaksanaan pembelajaran PKn berbasis karakter bangsa yang ada di SD 004Bangkinang terdiri dari tiga tahapan yaitu kegiatan pendahuluan, kegiatan inti dan kegiatan penutup. Kegiatan observasi yang dilakukan oleh peneliti di SD 004 Bangkinang 
tidak hanya dilaksanakan terhadap lingkungan sekolah tetapi juga di dalam kelas. Setelah mendapatkan ijin dari kepala sekolah kemudian, peneliti melakukan observasi di dalam kelas.

Para guru PKn di SD 004 Bangkinang membuka kegiatan pembelajaran dengan membaca doa dan menyanyikan lagu nasional yaitu lagu Indonesia Raya. Setelah itu guru melakukan apersepsi. Pada kegiatan ini guru memberikan gambaran atau bercerita mengenai suatu hal atau yang sedang terjadi saat itu untuk membawa siswa kemudian masuk ke dalam materi yang akan disampaikan oleh guru.

Setelah membaca doa dan menyanyikan lagu Indonesia Raya, kemudian dilanjutkan dengan kegiatan inti. Dalam pelaksanaan kegiatan inti mengacu pada Rencana Pelaksanaan Pembelajaran yang telah dibuat sebelumnya. Kegiatan inti terdiri dari kegiatan eksporasi, elaborasi dan konfirmasi. Eksplorasi adalah upaya awal membangun pengetahuan melalui peningkatan pemahaman atas suatu fenomena. Strategi yang digunakan memperluas dan memperdalam pengetahuan dengan menerapkan strategi belajar aktif. Elaborasi adalah mengenai desain pembelajaran dengan dasar argumen bahwa pelajaran harus diorganisasikan dari materi yang sederhana menuju pada harapan yang kompleks dengan mengembangkan pemahaman pada konteks yang lebih bermakna sehingga berkembang menjadi ide-ide yang terintegrasi. Dan konfirmasi merupakan yang dilakukan oleh guru untuk mengetahui pemahan siswa tentang materi yang telah diajarkan.

Metode pembelajaran yang digunakan oleh guru PKn sangat beragam biasanya disesuaikan dengan materi yang akan diajarkan oleh guru. Tapi pada umumnya yang digunakan adalah metode diskusi, tanya jawab dan latihan. Untuk metode diskusi kami dilakukan secara berkelompok biasanya untuk membahas suatu materi karena dengan berdiskusi mereka dapat berbagi informasi satu sama lain. Kalau tanya jawab siswa dapat bertanya kepada guru apabila materi yang diajarkan masih ada yang belum paham.

Siswa mulai bekerja dengan kelompoknya. Kelompok yang sudah siap kemudian mempresentasikan hasil kerja kelompok mereka di dapan kelas. Waktu presentasi adalah \pm 10 menit. Kemudian siswa yang lainnya diberikan kesempatan untuk menyampaikan tanggapan atau pertanyaan. Dan kelompok yang mempresentasikan wajib menjawab pertanyaan tersebut. Dalam kerja kelompok siswa belajar akan kerja sama demokrasi, kedisiplinan, yang merupakan nilai-nilai karakter bangsa yang akan ditanamnkan dalam pembelaaran PKn.

Interaksi yang terjadi ketika KBM berlangsung tidak hanya antara siswa dengan guru tetapi juga antara siswa dengan siswa. Interaksi antara guru dengan siswa merupakan interaksi yang positif yaitu siswa dan guru saling menghormati, saling menghargai saling tolong menoong serta sikap santun siswa terhadap guru. Sedangkan interaksi yang terjadi diantara siswa adalah adanya sikap toleransi, menghormati, menghargai, dan setia kawan. Interaksi juga terlihat ketika siswa saling berdikusi secara berkelompok dan saling bertanya satu sama lain. Dengan adanya interaksi tersebut maka dapat dilihat apakah siswa antusias dalm mengikuti KBM atau tidak, dan hal itu terlihat ketika guru menyampaikan materi seperti materi tentang hakikat bangsa dan unsur-unsur terbentuknya negara. Siswa tertarik untuk mendengarnya dan kemudian mengajukan pertanyaan tentang materi yang kurang dipahami.

Peran serta guru dalam kegiatan pembelajaran pendidikan kewraganegaraan memang sangat dibutuhkan. Alasanya adalah para guru memiliki pengalaman hidup lebih banyak sehingga mereka dapat berbagi dengan para siswa. Pentingnya peran serta guru dalam KBM juga diperkuat dengan penelitian dari Schugurensky, Daniel and Myers, John P. (2003) dalam penelitiannya yang berjudul "A Framework To Explore Lifelong Learning: The Case Of The Civic Education Of Civics Teachers". Penelitian ini membahas tentang pentingnya pendidikan kewarganegaraan di sekolah. Guru sebaagi tenaga pengajar memiliki tanggungjawab untuk memberikan materi yang berkaitan dengan kewarganegaraan sehingga rasa patriotisme siswa dapat meningkat. Hasil penelitian ini adalah pendidikan kewarganegaraan dapat dipelajari seumur hidup yaitu dari kecil sampai dewasa. Dan pendidikan kewarganegaraan dapat dipelajari dimana saja dan kapan saja. 
Terdapat persamaan dan perbedaan antara penelitian Schugurensky, Daniel and Myers, John P. (2003) dengan hasil penelitian. Persamaannya adalah guru memiliki peranan yang penting dalam proses KBM. Karena guru harus memahami materi apa yang akan diberikan sehingga rasa patriotisme siswa dapat meningkat. Perbedaannya adalah hasil penelitian menunjukkan untuk meningkatkan rasa patriotisme siswa dengan menanamkan nilai-nilai karakter bangsa pada setiap materi yang diberikan oleh guru.

Setelah kegiatan inti selesai dilaksanakan guru menutup proses KBM dengan membaca doa bersama dan mengucapkan salam sebelum meninggalkan ruang kelas. Tujuannya adalah agar siswa menjadi rileks lagi setelah mengikuti pembelajaran PKn. Sehingga mereka siap lagi untuk mengikuti pelajaran selanjutnya.

3. Karakteristik Evaluasi Pembelajaran Pkn Berbasis Karakter di SD 004 Bangkinang

Kegiatan pembelajaran PKn berbasis karakter bangsa membutuhkan adanya kegiatan evaluasi. Kegiatan tersebut untuk mengetahui hasil dari proses pembelajaran yang telah dilakukan, apakah hasilnya sudah sesuai dengan nilai Kriteria Ketuntasan Minimal (KKM) atau belum. Observasi peneliti dilapangan menunjukkan bahwa kegiatan evaluasi yang dilakukan guru PKn di SD 004Bangkinang terbagi menjadi dua penilaian yaitu penilaian kognitif dan penilaian afektif. Dalam penilaian kognitif guru memberikan soal-soal yang berhubungan dengan materi pelajaran dan penilaain afektif melalui perubahan sikap yang ditunjukkan siswa setelah mengikuti proses KBM.

Penelitian yang dilakukan oleh Berryhill (2007) yang berjudul "Comparative Implications of Character Education Programs in Public Schools in Arkansas". Nama jurnalnya Presentation Paper for the International Conference on Civic Education Research. Jenis penelitian ini adalah penelitian kuantitatif. Penelitian ini mengevaluasi pengaruh dari program pendidikan sekolah, pendidikan karakter pada perilaku siswa dan pada budaya iklim dan pada pelaksanaan sebelas prinsip karakter. Ada perbedaan yang terukur dalam mengamati perilaku siswa di sekolah PAR (implemntasi pendidikan karakter) dan NONPAR sekolah (tidak ada sekolah implementasi pendidikan karakter implementasi). Hasil penelitian ini menyatakan bahwa pelaksanaan program pendidikan karakter di semua sekolah umum di Arkansas akan menghasilkan karakter lebih tinggi skor, atau nilai akademik.

Terdapat persamaan dan perbedaan antara penelitian Berryhill (2007) dengan hasil penelitian. Persamaannya adalah pelaksanaan pendidikan karakter di sekolah mampu meningkatkan nilai siswa baik secara akademik maupun tingkah laku siswa. karena dalam pelaksannya diberikan pendidikan karakter. Sehingga pada saat evaluasi dilakukan nilai siswa semakin meningkat. Perbedaannya adalah tidak dijelaskan berapa persen peningkatan nilai untuk siswa yang menerima pendidikan karakter dengan siswa yang tidak menerimanya.

Untuk penilaian kognitif dilakukan dalm 3 kegiatan penilaian yaitu evaluasi awal atau pre test penilaian diawal KBM, evaluasi atau penilaian ketika proses pembelajaran sedang berlangsung dan post test atau evaluasi akhir penilaian diakhir KBM. Pelaksanaan evaluasi awal bertujuan untuk mengetahui kemampuan awal siswa mengenai pembelajaran yang bersangkutan. Di SD 004 Bangkinang dapat diketahui bahwa para guru di sekolah tersebut menggunakan evaluasi awal.

Untuk penilaian afektif guru memperhatikan sikap dan tingkah laku siswa di sekolah. Guru akan menilai perilaku dan sikap siswa sebelum dan sesudah menerima materi pelajaran. Nilai budaya dan karakter bangsa yang ingin dicapai dari pembelajaran PKn adalah siswa diharapkan memiliki sifat Religius, jujur, toleransi, disiplin, kerja keras, mandiri, demokratis, rasa ingin tahu, semangat kebangsaan, cinta tanah air, menghargai prestasi, bersahabat, cinta damai, gemar membaca, peduli lingkungan, peduli sosial, tanggung jawab.

Setelah dilakukannya evaluasi maka akan diketahui hasilnya dan bila hasil pembelajaran sudah diketahui maka akan memudahkan guru untuk melakukan kegiatan tindak lanjut. Pada umumnya guru akan melakukan tindak lanjut bagi siswa yang memiliki nilai kurang dari nilai Kriteria Ketuntasan Minimal (KKM) maka akan dilakukan 
remidi sedangkan bagi siswa yang nilainya sudah baik maka siswa akan mendapatkan penganyaan.

Di SD 004 Bangkinang kegiatan tindak lanjut yang dilakukan oleh guru setelah guru melakukan kegiatan evaluasi. Dari kegiatan evaluasi itulah dapat diketahui apakah siswa sudah menguasai materi pelajaran yang disampaikan oleh guru atau belum. Guru akan memberikan kegiatan tindak lanjut berupa remidi bagi siswa yang nilainya kurang dari 70 dan akan memberikan kegiataan pengayaan bagi siswa yang memiliki nilai lebih dari 70 .

Kegiatan remidial yang dilakukan oleh guru adalah kegiatan berupa pengulangan materi pelajaran PKn. Setelah pelaksanaan pengulangan materi kemudian guru akan memberikan soal untuk mengevaluasi apakah pengulangan materi tersebut sudah berhasil atau belum. Karena apabila siswa tersebut belum menguasai materi yang ada, hal itu dapat mengganggu proses belajar mengajar karena siswa yang sudah menguasai materi pelajaran tidak dapat meneruskan materi pelajaran.

\section{SIMPULAN}

Melalui kegiatan PKM ditarik kesimpulan sebagai berikut (1) Perencanaan pembelajaran Pkn berbasis karakter bangsa di SD 004 Bangkinang dilakukan dengan penyusunan RPP berdasarkan standar kompetensi (SK) dan kompetensi dasar (KD) mata pelajaran PKn terlebih dahulu. Tujuannya adalah agar memudahkan guru dalam memasukkan nilai-nilai karakter yang akan diberikan kepada siswa. Nilai-nilai karakter yang dicantumkan dalam RPP disesuaikan dengan SK. (2) Pelaksanaan pembelajaran PKn berbasis karakter bangsa terdiri dari tiga tahapan. Pelaksanaan pembelajaran di awali dengan kegiatan pembukaan yang terdiri dari pembacaan doa dan menyanyikan lagu nasional. Nilai karakter pada saat berdoa adalah iman dan taqwa, sedangkan menyanyikan lagu Indonesia Raya adalah rasa cinta tanah air. Kegiatan inti terdiri dari kegiatan eksplorasi, elaborasi dan konfirmasi. Nilai karakter untuk kegiatan ekplorasi antara lain rasa ingin tahu, semangat kebangsaan serta cinta tanah air. Nilai karakter untuk kegiatan elaborasi antara lain berani, percaya diri dan kerjasama. Setelah kegiatan inti selesai dilaksanakan guru menutup proses KBM dengan membaca doa bersama dan mengucapkan salam sebelum meninggalkan ruang kelas. (3) Kegiatan evaluasi pembelajaran PKn berbasis karater bangsa di SD 002 Bangkinangterbagi menjadi dua penilaian yaitu penilaian kognitif dan penilaian afektif. Penilaian kognitif dilakukan dengan memberikan soal kepada siswa sesuai dengan SK dan KD. Sedangkan untuk penilaian afektif dilakukan dengan menggunakan lembar observasi sesuai dengan niai-nilai karakter yang akan dicapai. Dari hasil penilaian afektif dapat diketahui ketercapaian penanaman nilai karakter bangsa dalam diri siswa.

\section{SARAN}

Berdasarkan hasil kegiatan PKM diharapkan kepada sekolah tempat penelitian, pengelolaan pembelajaran yang telah dilaksanakan dengan baik hendaknya dapat dipertahankan sehingga tujuan dari pembelajaran dapat tercapai.

\section{UCAPAN TERIMA KASIH}

Tim PKM menyampaikan ucapan terimakasih kepada semua pihak yang telah membantu pelaksanaan kegiatan ini yaitu: Dekan Fakultas Ilmu Pendidikan Universitas Pahlawan Tuanku Tambusai; Ketua LPPM, Kepala Sekolah SD 004 Bangkinang, dosen-dosen dan mahasiswa Universitas Pahlawan Tuanku Tambusai.

\section{DAFTAR PUSTAKA}

Abdulkarim A. 2004. Pendidikan Kewarganegaraan SD. Cet.1.

Bandung: Grafindo Media Pratama.

Berryhill. 2007. "Comparative Implications of Character Education Programs in Public

Schools in Arkansas". Journal of Education. Vol 1 No 1. Pg: 1-27. 
Budiyanto. 2006. Dasar-Dasar Ilmu Tata Negara. LAN

Hidayat, Kusnadi Supriadi. 2009. "Hubungan Manusia dan Budaya Pengertian Peran, Status, Nilai, Norma Dan Budaya/ Kebudayaan". http://kusnadish.blogspot.com/2011/02/hubungan-manusia-dan-

budaya-pengertian.html. Diakses tanggal 17 Februari 2012.

Huitt. 2010. "A Holistic View of Education and Schooling: Guiding Students to Develop Capacities, Acquire Virtues, and Provide Service". Journal of Education and Research. Vol 1 No 1. Pg: 1-30.

Kennedy, Kerry J. 2002. "Teachers' Conversations about Civic Education: Policy and Practice in Australian Schools". Journal of Asia Pacific Education. Vol. 3, No. 1. Pg: 69-82.

Moleong. 2001. Metodologi Penelitian Kualitatif. Bandung: PT Remaja Rosdakarya.

Singh dan Mr. A.R. Agwan, Encyclopaedia of the Holy Qur'ân. New Delhi: balaji Offset, 2000.

Sudrajat, Akhmad. 2010. "Konsep Pendidikan Karakter". http://akhmadsudrajat.wordpress.com/2010/09/15/konsep- pendidikan-karakter/. Diambil pada tanggal 24 April 2010

Spradley, James P. 2007. Metode Etnografi. Yogyakarta: Tiara wacana

Sim, Jasmine Boon-Yee. 2005. "Citizenship Education And Social Studies In Singapore: A National Agenda". International Journal of Citizenship and Teacher Education. Vol 1. No.1 Pg: 58-73

Schugurensky, Daniel and Myers, John P. 2003. "A Framework To Explore Lifelong Learning: The Case Of The Civic Education Of Civics Teachers". Journal of Lifelong Education. Vol. 22, No. 4. Pg: $325-352$

Undang - Undang Republik Indonesia No. 20 Tahun 2003 Tentang Sistem Pendidikan Nasional. Semarang: Aneka Ilmu 